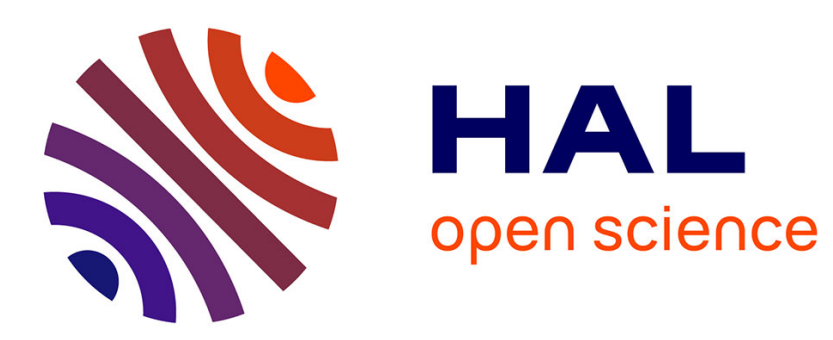

\title{
Remote sensing estimates of glacier mass balances in the Himachal Pradesh (Western Himalaya, India).
}

\author{
E. Berthier, Y. Arnaud, K. Rajesh, A. Sarfaraz, P. Wagnon, P. Chevallier
}

\section{To cite this version:}

E. Berthier, Y. Arnaud, K. Rajesh, A. Sarfaraz, P. Wagnon, et al.. Remote sensing estimates of glacier mass balances in the Himachal Pradesh (Western Himalaya, India).. Remote Sensing of Environment, 2007, 108 (3), pp.327-338. 10.1016/j.rse.2006.11.017 . hal-00280179

\section{HAL Id: hal-00280179 \\ https://hal.science/hal-00280179}

Submitted on 5 Aug 2009

HAL is a multi-disciplinary open access archive for the deposit and dissemination of scientific research documents, whether they are published or not. The documents may come from teaching and research institutions in France or abroad, or from public or private research centers.
L'archive ouverte pluridisciplinaire HAL, est destinée au dépôt et à la diffusion de documents scientifiques de niveau recherche, publiés ou non, émanant des établissements d'enseignement et de recherche français ou étrangers, des laboratoires publics ou privés. 


\title{
Remote sensing estimates of glacier mass balances in the Himachal Pradesh (Western Himalaya, India)
}

\author{
Berthier Etienne*, Arnaud Yves, Kumar Rajesh, Ahmad SARfaraz, \\ WAGNON PATRICK \& CHEVALLIER PIERRE.
}

*Corresponding author:

Etienne Berthier

Etienne.berthier@legos.obs-mip.fr

To be cited as :

Berthier E., Arnaud Y., Rajesh K., Sarfaraz A., Wagnon P., \& Chevallier P., Remote sensing estimates of glacier mass balances in the Himachal Pradesh (Western Himalaya, India). Remote Sensing Environ., 108(3), 327-338, doi:10.1016/j.rse.2006.11.017, 2007

The ELSEVIER Remote Sensing of Environment version of the paper is available at: http://dx.doi.org/10.1016/j.rse.2006.11.017 


\begin{abstract}
Although they correspond to an important fraction of the total area of mountain glaciers $\left(33000 \mathrm{~km}^{2}\right.$ out of $546000 \mathrm{~km}^{2}$ ), Himalayan glaciers and their mass balance are poorly sampled. For example, between 1977 and 1999, the average area surveyed each year on the field was $6.8 \mathrm{~km}^{2}$ only. No direct mass balance measurement is available after 1999 . To contribute to fill this gap, we use remote sensing data to monitor glacier elevation changes and mass balances in the Spiti/Lahaul region $\left(32.2^{\circ} \mathrm{N}, 77.6^{\circ} \mathrm{E}\right.$, Himachal Pradesh, Western Himalaya, India). Our measurements are obtained by comparing a 2004 digital elevation model (DEM) to the 2000 SRTM (Shuttle Radar Topographic Mission) topography.
\end{abstract}

The 2004 DEM is derived from two SPOT5 satellite optical images without any ground control points. This is achieved thanks to the good on-board geolocation of SPOT5 scenes and using SRTM elevations as a reference on the ice-free zones. Before comparison on glaciers, the two DEMs are analyzed on the stable areas surrounding the glaciers where no elevation change is expected. Two different biases are detected. A long wavelength bias affects the SPOT5 DEM and is correlated to an anomaly in the roll of the SPOT5 satellite. A bias is also observed as a function of altitude and is attributed to the SRTM dataset. Both biases are modeled and removed to permit unbiased comparison of the two DEM on the $915 \mathrm{~km}^{2}$ ice-covered area digitized from an ASTER image.

On most glaciers, a clear thinning is measured at low elevations, even on debris-covered tongues. Between 1999 and 2004, we obtain an overall specific mass balance of - 0.7 to $0.85 \mathrm{~m} / \mathrm{a}$ (water equivalent) depending on the density we use for the lost (or gained) material in the accumulation zone. This rate of ice loss is twice higher than the long-term (1977 to 1999) mass balance record for Himalaya indicating an increase in the pace of glacier wastage. To assess whether these ice losses are size-dependant, all glaciers were classified into three samples according to their areal extent. All three samples show ice loss, the loss being higher for glaciers larger than $30 \mathrm{~km}^{2}$. In the case of the benchmark Chhota Shigri glacier, a good agreement is found between our satellite observations and the mass balances measured on the field during hydrological years 2002-2003 and 20032004. Future studies using a similar methodology could determine whether similar ice losses have occurred in other parts of the Himalaya and may allow evaluation of the contribution of this mountain range to ongoing sea level rise. 


\section{Introduction}

Covering over $33000 \mathrm{~km}^{2}$, glaciers constitute an important component of the Himalaya (Kaul et al., 1999; Dyurgerov and Meier, 2005). Monitoring their evolution is a key issue as the melting of all glaciers in central Asia may significantly contribute to ongoing sea level rise (Kaser et al., 2006). Changes in glacier length, areal extent or mass balance can also be used as climate indicators in a region where climatic series (temperature, precipitation) are rare and the climate change signal is not clear (Yadav et al., 2004 ; Roy and Balling, 2005). In addition, runoff generated by the melting of these glaciers is an important source of water for the people living in the Himalayan valleys (WWF, 2005). Measuring ongoing glacier wastage is a first step toward the prediction of future water resources in this area and has, thus, important social and economical impacts (Barnett et al., 2005).

Yet, mass balance of Himalayan glaciers is very poorly sampled on the field. One of the most recent and comprehensive global inventories includes only 8 glaciers in India and 3 in Nepal with mass balances measured for at least one year (Dyurgerov and Meier, 2005). These 11 glaciers cover a total area of $121 \mathrm{~km}^{2}$. This area decreases to $46 \mathrm{~km}^{2}$ when excluding the Langtang glacier (Nepal, $75 \mathrm{~km}^{2}$ ) whose mass balance is not measured directly in the field but modeled from temperatures and precipitations measured in Kathmandu, $60 \mathrm{~km}$ away (Tangborn and Rana, 2000). Furthermore, the time series are short with a mean duration of about 5 years (4.3 years without Langtang glacier) and no mass balance measurement has been reported since 2000 (Dyurgerov and Meier, 2005). On average between 1977 and 1999, the glacier area monitored each year is limited to 6.8 $\mathrm{km}^{2}$ out of about $33000 \mathrm{~km}^{2}$.

Given the size and remoteness of glaciers in Himalaya, satellite imagery is a suitable means to obtain a comprehensive and more frequent sampling of their evolution (Bishop et al., 2000). Remote sensing studies in this region mainly aim at establishing digital glacier inventories (Kargel et al., 2005) to track the changes in glacier surface when compared to older map-based inventories (Kaul et al, 1999). Also, the recent and rapid growth of some supra-glacial and moraine-dammed lakes in the central and eastern Himalaya has been detected from multispectral (in particular ASTER) images (Wessels et al., 2002; Kargel et al., 2005). The historical variations of these glacier lakes and glacier termini in Bhutan have been examined using satellite, photographs and maps (Ageta et al., 2000). Remote sensing studies based on SPOT images have concentrated on observing surface features of Khumbu glacier, Nepal Himalaya (Seko et al., 1998) or Batura glacier in Pakistan (Bishop et al., 1995). Recently, Kääb (2005) combined ASTER and SRTM (Shuttle Radar Topographic Mission) data to produce a synthetic digital elevation model (DEM) and then map the contrasted dynamical behavior of glaciers in the northern and southern flanks of the main mountain ridge in Bhutan (East Himalaya).

Yet, only very few remote sensing studies addressed the crucial question of glacier mass balance. Based on field measurements, Kulkarni (1992) established the relationship between the specific mass balance and the accumulation area ratio (AAR) or the equilibrium line altitude (ELA) for two glaciers (Gara and Gor-Gorang glaciers) in the 
Himachal Pradesh ${ }^{1}$. Thanks to this relationship, and assuming that the snowline at the end of the melting season (September) indicates the ELA, Kulkarni et al. (2004) proposed to estimate the mass balance of these two glaciers using Landsat images. However, the extrapolation to other glaciers not sampled on the field is problematic because this relationship is different from one glacier to another. This is illustrated in the Figure 3 of Kulkarni (1992) by the measurements labeled T-83, S-84 N-82, K-84 and T-84: for a similar mass balance (about $-0.3 \mathrm{~m}$ w.e.), the AAR is ranging from 0.2 to 0.5 , highlighting the uncertainties associated with this method of measuring glacier mass balance from space.

The aim of this paper is to present the first space-based measurement of glacier elevation changes in the Himalaya. Our measurements are achieved by adjusting and comparing the SRTM February 2000 topography and a digital elevation model (DEM) derived from a pair of SPOT5 satellite images acquired in November 2004 (section 2). A specific methodology is developed to derive a DEM from SPOT5 images without any ground control points (GCPs) and to cope with the biases detected in the two compared DEMs (section 3). We then derive the specific mass balance of $915 \mathrm{~km}^{2}$ of glaciers located in the Spiti/Lahaul region in the Himachal Pradesh, Western Himalaya (section 4). This study area (Figure 1 and Figure 2) deserves a special attention. The occurrence of global warming in the Western Himalaya is still under debate (Yadav et al., 2004; Roy and Balling, 2005) and glacier retreat seems to be limited (Kargel et al., 2005). Furthermore, the mass balance of one benchmark glacier, Chhota Shigri (Kumar and Dobhal, 1997), has been measured on the field since 2002 (Wagnon et al., in preparation) and can be used for comparison.
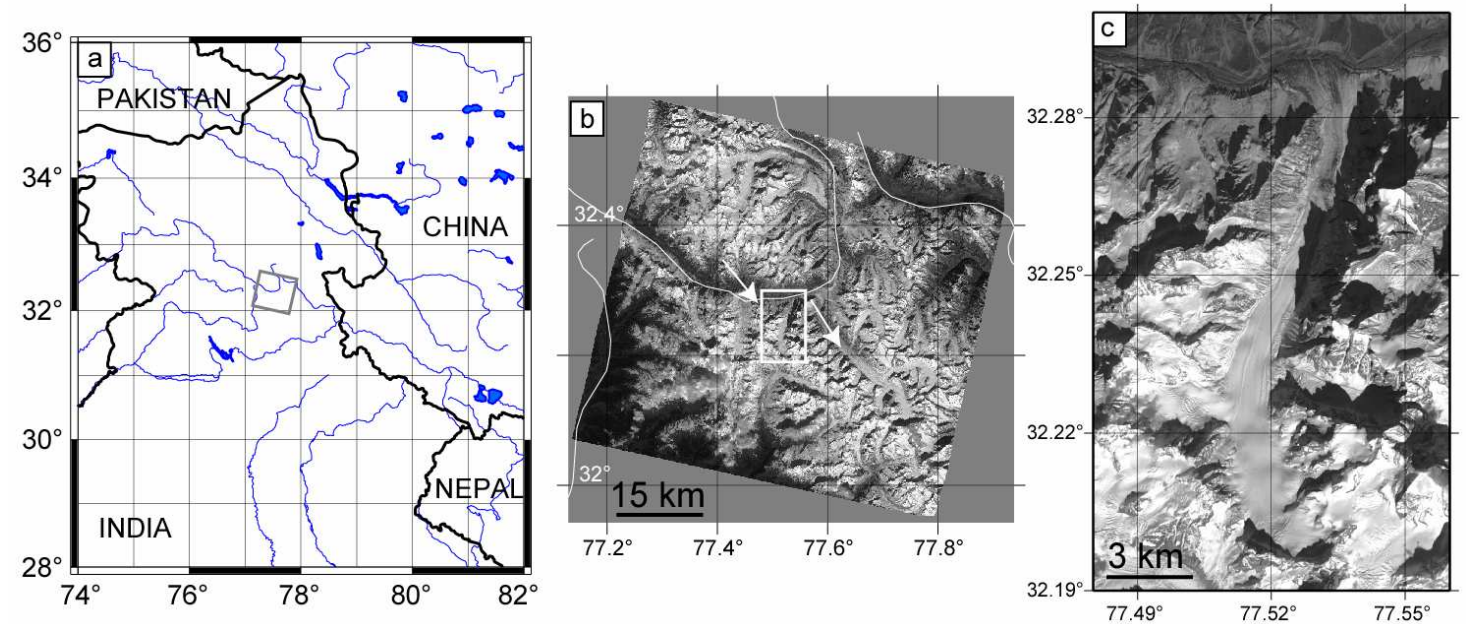

Figure 1: Study area: Spiti/Lahaul region in the Himachal Pradesh $\left(32.2^{\circ} \mathrm{N}, 77.6^{\circ} \mathrm{E}\right)$. (a) Location map including the footprint (grey rectangle) of the SPOT5 images. (b) 12 November 2004 SPOT5 image with the main rivers. The arrows indicate the point of view for the $3 D$ perspectives presented in Figure 2 and the white rectangle locates the Chhota Shigri glacier shown in (c). Note the shadows due to the steep valley walls and the low solar illumination in late autumn.

\footnotetext{
${ }^{1}$ We noted an error in the specific mass balance presented in this article: $\mathrm{cm}$ should be replaced by $\mathrm{dm}$
} 

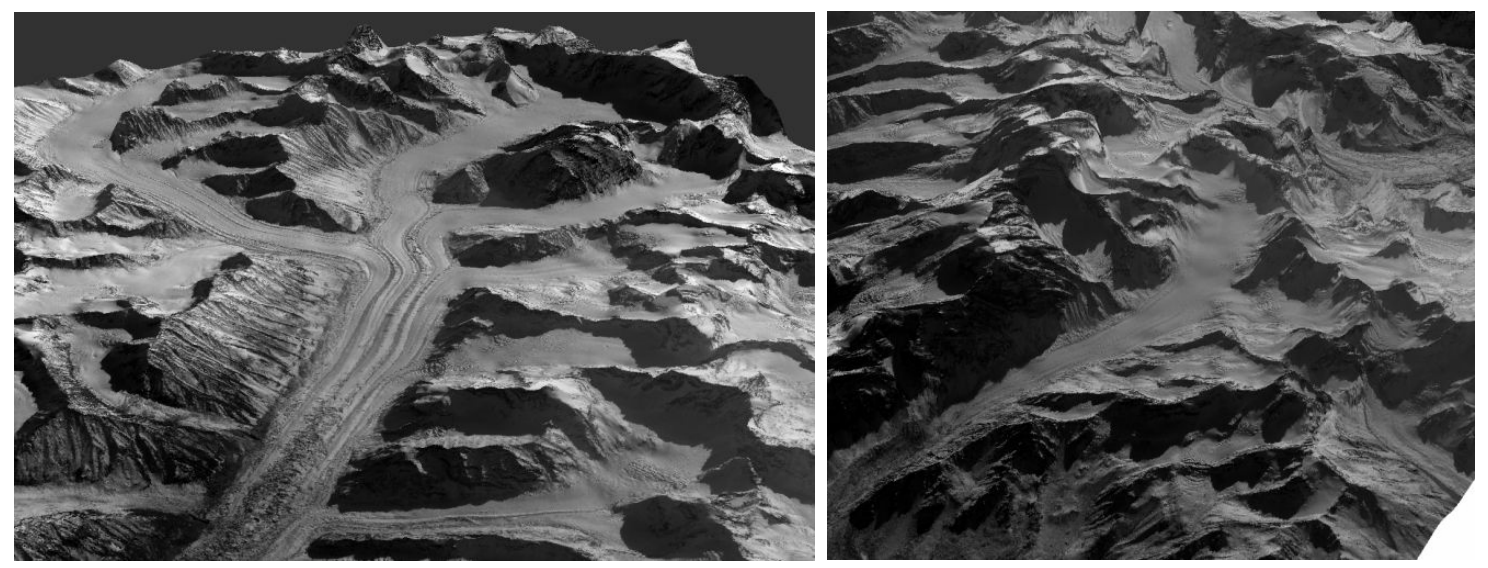

Figure 2: Synthetic perspective view of the Bara Shigri (left panel) and Chhota Shigri (right panel) glaciers obtained by draping a SPOT5 image over a DEM. No vertical exaggeration. Note the rough surface of the debris-covered tongue of Bara Shigri and the occurrence of fresh snow on the slopes surrounding the glaciers.

\section{Data : Satellite images, SRTM-DEM and field data}

\subsection{SPOT5 images}

Two images were acquired on 12 and 13 November 2004 by the SPOT5-HRG (Haute Résolution Géométrique) sensor in panchromatic (THR) mode. The ground resolution at nadir is $2.5 \mathrm{~m}$ and the gain of the sensor was set to 1 to avoid saturation on the highly reflective snow-covered upper reaches of the glaciers. The characteristics of the images are summarized in Table 1 . The short time separation (1 day) results in limited changes on and off the glaciers and thus ensures a good correlation between the two images. The opposite across-track incidence angles lead to a base-to-height ratio $(\mathrm{B} / \mathrm{H})$ of 0.61 , which is suitable for DEM generation in high mountain areas (Toutin, 2002). A higher base-toheight ratio would be advantageous for the accuracy of the SPOT5-DEM on gentle slopes but would also lead to stronger distortions between the images and consequently more gross errors and data voids on steep slopes. Due to important cloud coverage at the end of the ablation season (September, October) and satellite schedule constraints, these SPOT5 scenes were acquired late (mid-November) and a snowfall occurred a few days before their acquisition (Figure 2). Visual inspection of the images indicates that the amount of snow seems to be limited, leading to small effect on the derived elevations. However, this recent snowfall makes the delimitation of glacier boundaries difficult. For this reason, glaciers are digitalized from an ASTER image.

Table 1: Characteristics of the SPOT5 and ASTER images used in this study.

\begin{tabular}{llllll}
\hline Satellite & Sensor & ID & Date & Resolution & Off-track angle \\
\hline TERRA & ASTER & AST_L1B.003:2009039954 & 28/09/2002 & $15 \mathrm{~m}$ & vertical \\
\hline SPOT5 & HRG & 52052850411120554051A & $12 / 11 / 2004$ & $2.5 \mathrm{~m}$ & 20.04 \\
\hline SPOT5 & HRG & 52052850411130534501A & $13 / 11 / 2004$ & $2.5 \mathrm{~m}$ & -13.9 \\
\hline
\end{tabular}




\subsection{ASTER image}

A (nearly) cloud free ASTER image was acquired on 28 September 2002 by the TERRA satellite. This image was obtained thanks to the GLIMS (Global Land Ice Measurement from Space) program (Kargel et al., 2005). The $15 \mathrm{~m}$ ground resolution of the Visible and Near Infra Red (VNIR) channels is adapted for glacier mapping (Kargel et al., 2005).

\subsection{SRTM-DEM}

The SRTM mission was flown in February 2000 and acquired C-Band $(5.6 \mathrm{~cm})$ synthetic aperture radar (SAR) images of the Earth surface between $60 \mathrm{~N}$ to $56 \mathrm{~S}$. These images were processed using SAR interferometry to obtain a nearly global DEM (Rabus et al., 2003). The SRTM-DEM of our study area was produced by merging 4 tiles covering each $1^{\circ}$ by $1^{\circ}$ and downloaded at ftp://e0srp01u.ecs.nasa.gov (SRTM3, version 2). The resolution is 3 arc second, about $92 \mathrm{~m}$ in latitude and $79 \mathrm{~m}$ in longitude in our region. Due to the acquisition geometry of the SAR data, the SRTM-DEM presents data voids in this high relief area. The 1-standard deviation error of the SRTM-DEM over Eurasia has been found to be $8.8 \mathrm{~m}, 6.2 \mathrm{~m}$ and $8.7 \mathrm{~m}$ for, respectively, the absolute geolocation, absolute height, and relative height (Rodriguez et al., 2006). These errors are higher for the steep topography of our study area, as shown by the comparison of SRTM with ICESAT elevation profiles (Carabajal and Harding, 2006). Errors correlated to altitude (Berthier et al., 2006) and slope (Surazakov and Aizen, 2006) have also been detected in high mountain regions. These errors in the SRTM-DEM will limit the accuracy of our measurements of elevation changes. The methodology we present in this paper aims at minimizing these errors by adjusting precisely the SRTM and the SPOT5 DEMs using stable areas surrounding glaciers.

\subsection{Field measurements}

Five field campaigns have already been performed by a joined Indian-French research team to monitor the mass balance of the Chhota Shigri glacier (about $16 \mathrm{~km}^{2}$ ). A network of 14 to 26 stakes and pits located between 4300 and $5500 \mathrm{~m}$ asl is surveyed annually at the end of the ablation season (late September, early October) to determine the specific mass balance. Here we use the mass balances available for hydrological years 2002-2003 and 2003-2004. Further details on the method and the complete series of mass balance will be given in a paper currently in preparation (Wagnon et al., in preparation).

\section{Computation and adjustment of the DEMs}

\subsection{Production of the SPOT5-DEM}

A DEM is calculated from the SPOT5 image pair using the PCI-Geomatica software. A first step in the production of a DEM is the computation of the satellite stereo model, usually using ground control points (GCPs). The stereo model determines the correct 
ground position of each point in the satellite image (Toutin and Cheng, 2002). For our study area, no precise map is available to the public in order to extract these GCPs. Given the absence of any real road network, it is nearly impossible to acquire a well-distributed set of GCPs on the field as recommended by Toutin (2004). Instead, we automatically generate GCPs by taking advantage of the accurate geolocation of the SPOT5 images and the availability of the SRTM topography (Figure 3). Indeed, thanks to precise onboard measurements of satellite positions and attitudes, the orbit of the SPOT5 satellite is wellknown, so that each pixel in a SPOT5 image can be located on the ground with an accuracy of $+/-25 \mathrm{~m}$ at the $66 \%$ confidence level (Bouillon et al., 2006 ; Reinartz et al., 2006).

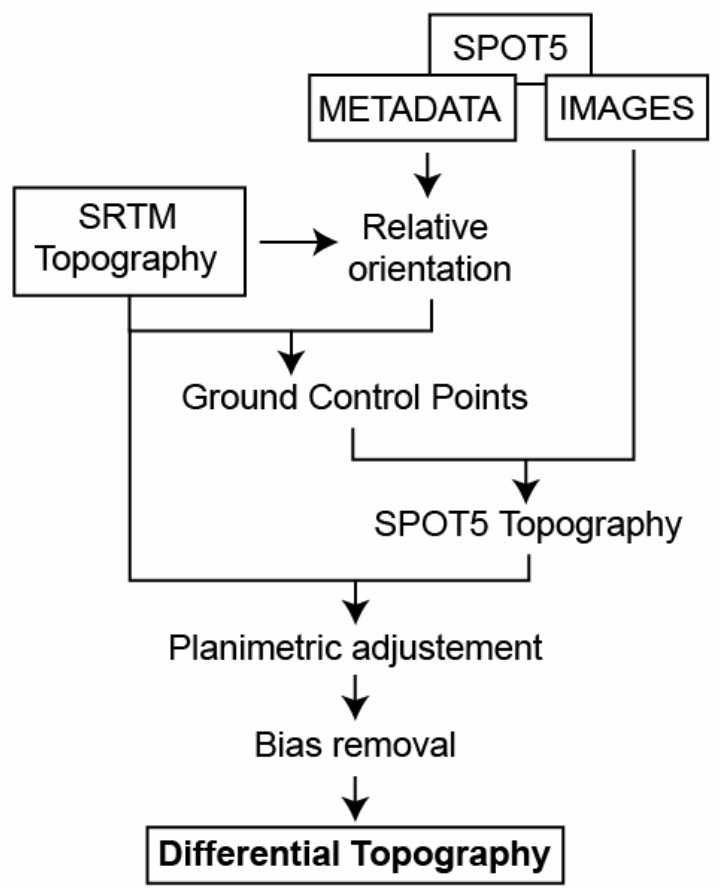

Figure 3: Flowchart of the methodology followed to extract a DEM from two SPOT5 images without ground control points.

The automatic extraction of GCPs starts with the relative orientation of the two SPOT5 images. The relative orientation ensures that a given image feature (or pixel) has the same ground coordinates in the two images. The 12 November 2004 image is chosen (arbitrary) as reference, and the stereo model of the 13 November 2004 image is improved. The relative orientation is based on homologous points extracted by cross correlation of the two images and takes into account the precise description of the SPOT5 orbits and attitudes provided with each image. It uses a group of software (MEDICIS, SP5LIB, OUST) that performs the image correlation and includes the description of the SPOT5 HRG sensor (SPOT image, 2002). These programs are currently only available through the French Space Agency (Centre National d'Etudes Spatiales, CNES). We do not present here the details of this step that has been described in a previous study where two SPOT5 images acquired a few weeks apart were coregistred within a fraction of pixel to monitor glacier surface displacements (Berthier et al., 2005). 
A set of about 100 well-distributed GCPs is then generated automatically for each image by using the stereo model of the reference SPOT5 image, the improved stereo model of the secondary image and SRTM elevations. The geographic coordinates of an image pixel is computed as the intersection between the satellite line of sight and the surface topography. A manual editing is necessary to remove all the GCPs located on glaciers, because of glacier elevation changes occurring between February 2000 (SRTM acquisition date) and November 2004 (date of SPOT5 images). GCPs located on the steepest slopes or close to SRTM data voids are also excluded because the elevations of these areas are less reliable (Surazakov and Aizen, 2006). The vertical accuracy of the GCPs is conditioned by the one of SRTM, in the order of $+/-18 \mathrm{~m}$ in the high mountains of Asia (Carabajal and Harding, 2006). Their planimetric accuracy is similar to the one of the SPOT5 stereo model, +/- $25 \mathrm{~m}$, which seems low compared to the $2.5 \mathrm{~m}$ resolution of the images. Yet, if a planimetric shift exists, its magnitude is similar for all the GCPs. Consequently, these GCPs are highly consistent between each others: in the PCIGeomatica project, the root mean square (RMS) errors are only 0.84 pixels (i.e. $2.1 \mathrm{~m}$ ) for the 12 November image and 0.67 pixels (i.e. $1.7 \mathrm{~m}$ ) for the 13 November scene.
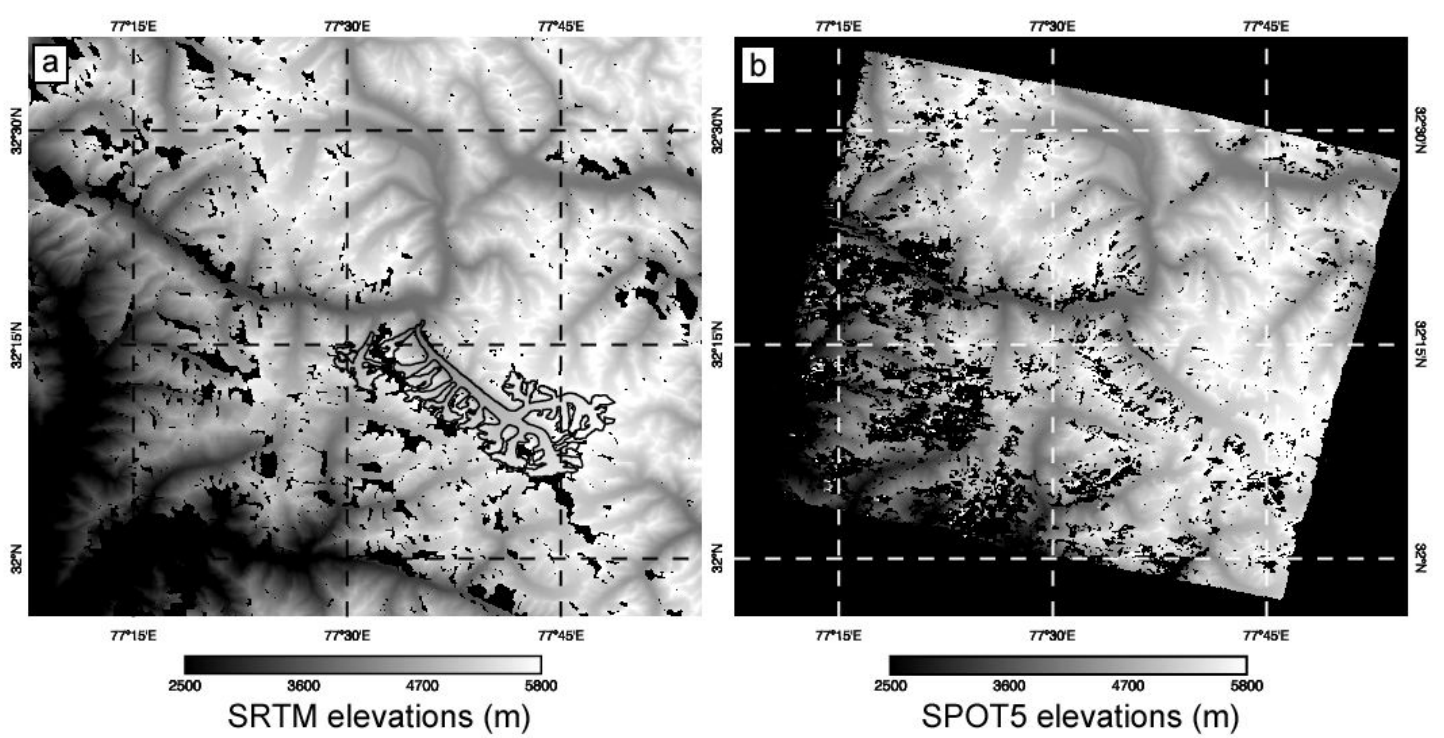

Figure 4: SRTM (a) and SPOT5 (b) DEMs. The boundaries of the Chhota Shigri $\left(16.5 \mathrm{~km}^{2}\right)$ and the Bara Shigri $\left(133 \mathrm{~km}^{2}\right)$ glaciers are overlaid in dark on the SRTM-DEM.

The SPOT5-DEM is then generated following the standard procedure in PCI-Geomatica: conversion to epipolar geometry, correlation of epipolar images, conversion of parallaxes to elevations and geocoding (Toutin and Cheng, 2002). The SPOT5-DEM is calculated at the same resolution (3 arc second) as the SRTM-DEM. As demonstrated previously by Kääb (2005), the choice of a DEM resolution coarser (about $90 \mathrm{~m}$ ) than the image resolution $(2.5 \mathrm{~m})$ leads to less gross errors and also less data voids. The SRTM and SPOT5 DEMs are presented in Figure 4. Despite a snowfall prior to the acquisition of SPOT5 images, the SPOT5-DEM was calculated over most of the images, in particular in the upper accumulation basins of glaciers. This is due to (1) the low gain of the images 
ensuring a good radiometric dynamics even on the snow-covered areas and (2) the short time separation (1 day), limiting surface changes. The low solar elevation angle in November (about $40^{\circ}$ ) combined with the steep slopes leads to some important shadows in the images resulting in gaps in the SPOT5-DEM. These gaps, covering about $20 \%$ of the DEM, are not filled by interpolation as we prefer no value of elevation than a value mainly conditioned by the interpolation scheme. Large errors (blunders), due to mismatches during the correlation, are detected by identifying the pixels where the absolute difference with SRTM-DEM was greater than $50 \mathrm{~m}$. These pixels are considered as missing value $(\mathrm{NaN})$ in the following.

\subsection{Planimetric adjustment of the DEMs}

The uncertainties $(+/-25 \mathrm{~m})$ in the geolocation of the SPOT5 reference image will propagate in all the steps of the DEM generation and can lead to a shifted SPOT5-DEM. To determine the value of the mean shift in latitude and longitude, we assume here that this shift is constant throughout the DEM and that SRTM-DEM is well geolocated, the later being true within $+/-10 \mathrm{~m}$ for $90 \%$ of the tiles (Rodriguez et al., 2006).

The correlation of the two DEMs, described by Kääb et al. (2005), was not successful because of numerous data voids in both DEMs. Instead, we determine the mean shift by minimizing the standard deviation of the difference between the two DEMs outside glaciers, similarly to what was done to evaluate geolocation errors of SRTM-DEM (Rodriguez et al., 2006). The process is illustrated in a one dimensional case by extracting a similar profile on the two DEMs (Figure 5a). When shifting the SPOT5 profile by some fractions of pixels (ranging from -2 to +2 pixels), we observe that the mean difference between the SPOT5 and SRTM DEMs varies monotonically whereas a clear minimum exists in the standard deviation of the difference (Figure 5b). Because our area presents a very rugged relief, the $\mathrm{X}$-coordinate of this minimum can be considered as the horizontal shift for which the valleys and the ridges correspond in the two topographies. Applied to the two dimensional case, this minimization permits finding the mean horizontal shift between the two DEMs (Figure 5c). The mean shift is 0.13 pixels in longitude (i.e. $9.9 \mathrm{~m}$ ) and 0.24 pixels in latitude (i.e. $21.6 \mathrm{~m}$ ). If we assume that the SRTM-DEM is well geolocated, the total horizontal shift of the SPOT5 reference scene is $23.7 \mathrm{~m}$, within the specification of the sensor (Bouillon et al., 2006). This reduced shift is also an a posteriori verification of our methodology to extract GCPs: a limited error in the geolocation of the SPOT5 reference scene is required to avoid large errors in the GCP elevations extracted from the SRTM-DEM. 

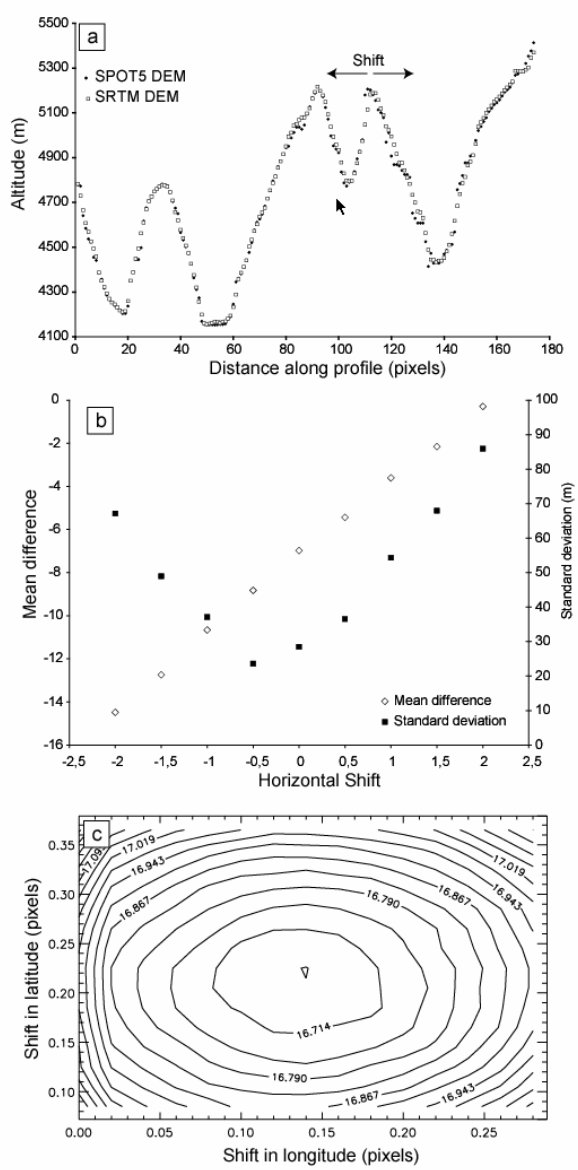

Figure 5: Estimate of the planimetric shift between the two DEMs. The method is illustrated first using a profile on the two upper panels and then applied to the real case on the lower panel. (a) Comparison of SRTM and SPOT5 elevations along a profile in a non-glaciarized area. (b) The SPOT5 profile shown in the upper panel is shifted by fractions (0.5) of pixel. For each value of this shift, the mean difference \{SPOT5-SRTM\} and standard deviation of this difference is given. (c) Contour plot of the standard deviation of the difference \{SPOT5-SRTM\} for different value of shifts in latitude and longitude. The minimum in this contour plot indicates the mean horizontal shift between the two DEMs.

\subsection{Identification \& correction of the biases between the two DEMs}

The difference between the two DEMs (SPOT5 - SRTM) is then computed pixel by pixel and first analysed on the ice free areas where no elevation change is expected in 5 years. For this purpose, a glacier inventory is produced from an ASTER image (see section 4.1) and is used to mask all the ice-covered regions.

Overall, the mean difference off glaciers is $0.43 \mathrm{~m}$, SPOT5 being slightly higher. The standard deviation of $16.7 \mathrm{~m}$ is in agreement with what has been previously reported in the French Alps (Berthier et al., 2006). Yet, the pattern of elevation changes shows some unexpected features (Figure 6a). A band of SPOT5 elevations higher than SRTM is clearly observed. This band is oriented parallel to the column of the SPOT5 images (see 
definition of lines and columns in Figure 6a) which makes us suspect an anomaly in the attitudes (rolls, pitch or yaw) of the satellite. To better visualize this bias, we extract parallel profiles of elevation changes oriented in the line direction (so perpendicular to the bias) and stack them. The resulting mean profile highlights clearly an area (around line number 200) where the SPOT5-DEM is 10 to $12 \mathrm{~m}$ higher than SRTM-DEM (Figure $6 b)$.
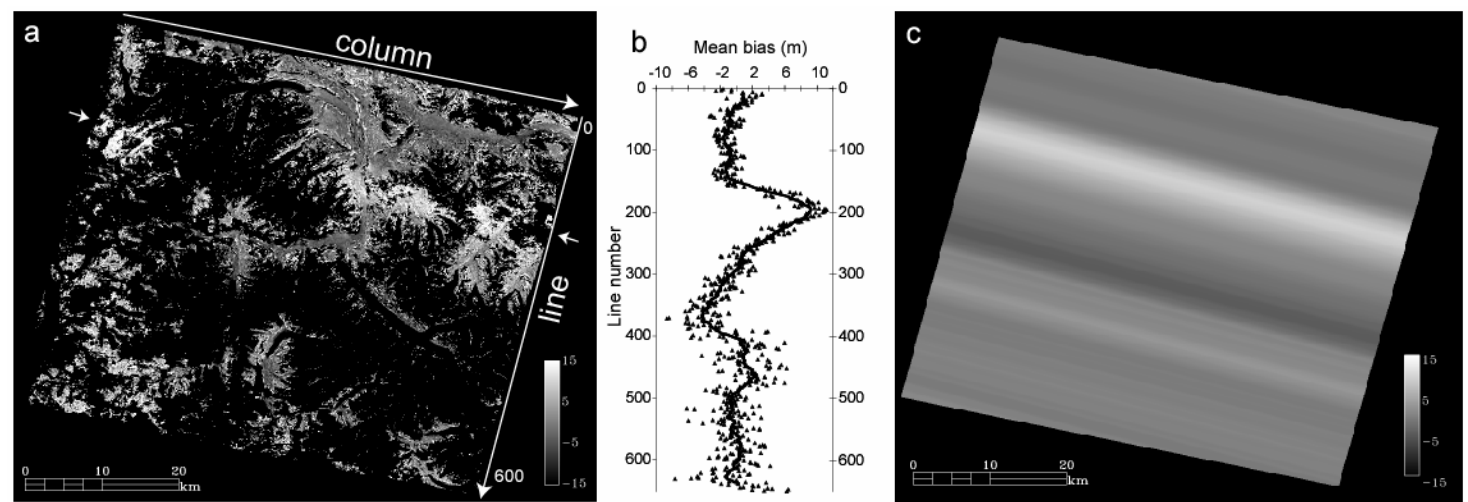

Figure 6: Bias in the SPOT5-DEM due to an anomaly in the satellite attitude and its correction. (a) Map of elevation differences \{SPOT5-SRTM\} on the ice free areas. The column and line directions of the SPOT5 images are indicated. The two small white arrows indicate a band where SPOT5 elevations are systematically higher than SRTM. The glaciers have been masked. (b) Biases between the two DEMs as a function of the line number. The solid line indicates a running mean over 31 lines (about $2.8 \mathrm{~km}$ ). (c) Map of the modeled bias derived from the solid line in (b). The color scale is identical in (a) and (c).

In figure 7, we compare the biases between the two DEMs and the evolution of the roll of the SPOT5 satellite along its trajectory while acquiring the 12 November 2004 image. The values of the roll have been extracted from the metadata provided with the SPOT images. The similarities between the two curves are striking. Positive anomalies in the roll of the satellite are associated with positive differences between the DEMs. Around line number 200 , the roll is about $-2.2 * 10^{-4}$ radian compared to a mean value of $-2.3 * 10^{-4}$ radian for the rest of the SPOT5 image. The approximate shift on the ground due to this change in the roll is obtained by multiplying the roll anomaly $\left(10^{-5}\right.$ radian) by the altitude of the SPOT5 satellite $(832 \mathrm{~km})$. Consequently, for this zone of the 12 November 2004 SPOT5 image, the pixels are shifted by about $8 \mathrm{~m}$ in the column direction. The resulting errors in the SPOT5 elevations are roughly obtained by dividing this horizontal shift by the base-to-height ratio $(\mathrm{B} / \mathrm{H}=0.61)$ for this pair of image (Toutin, 2002). The predicted error is of the order of $13 \mathrm{~m}$. This is similar to the amplitude of the bias (about $12 \mathrm{~m}$ ) between the two DEMs around line 200 (Figure 7). This simple calculation confirms that anomalies in the roll of the 12 November 2004 SPOT5 satellite are responsible for the line-oriented biases between the two DEMs. Note that the anomalies of the roll of the 13 November 2004 image and of the pitch and yaw (the two other parameters describing the attitude of satellite) for both SPOT5 images are nearly an order of magnitude smaller than the roll anomalies of the 12 November 2004 image and, consequently, have a limited effect on the SPOT5-DEM. 


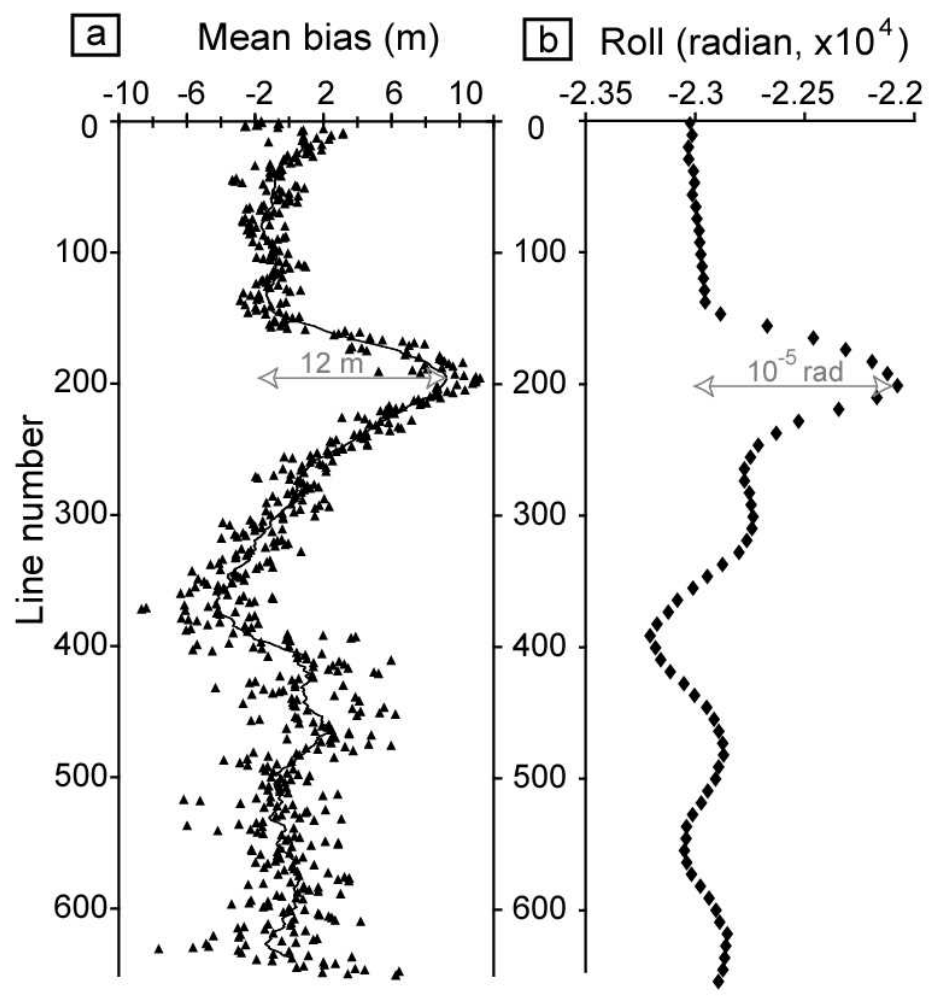

Figure 7: (a) Biases between the two DEMs (same as Figure 6b) compared with (b) the attitudes of the SPOT5 satellite while acquiring the 12 November 2004 image.

The PCI-Geomatica software does not take into account the changes in satellite attitudes along the orbit although they are provided with SPOT5 images (Cheng, personal communication). This is why anomalies in the roll of one of the two SPOT5 images lead to errors in our SPOT5-DEM. Ideally, the measurement of attitudes given in the metadata should be taken into account in a physical rigorous stereo model of SPOT5 images. As, to our knowledge, this functionality is not currently implanted in any commercial software, we perform an empirical correction of the bias in the SPOT5-DEM. We assume that the bias is identical along each column (as defined in Figure 6a) of the SPOT5-DEM. We model the bias as the 31-line running mean of the difference between the SPOT5 and SRTM DEMs (solid line in Figure 6b). We produce the synthetic error map shown in Figure 6c. These errors are then removed from the SPOT5-DEM in both the glaciarized and non-glaciarized regions.

Some systematic biases of SRTM-DEM have recently been detected as a function of altitude in the French northern and southern Alps where SRTM elevations were shown to be underestimated on ridges/summit and overestimated in the valleys (Berthier et al., 2006). To detect the occurrence of similar biases in the Spiti/Lahaul region, we compute the mean difference between SRTM and SPOT5 DEMs off the glaciers for each altitude range, and then plot these differences as a function of altitude (Figure 8). A linear trend is fitted to quantify any bias with altitude. As in the French Alps, the SRTM-DEM is higher (respectively lower) than the SPOT5-DEM at low (respectively high) elevations. The bias with altitude is $-8 \mathrm{~m}$ every $1000 \mathrm{~m}$ when all elevations are taken into account and $-6.4 \mathrm{~m} /$ 
$1000 \mathrm{~m}$ when the lowest and highest points (unfilled squares in Figure 8) are excluded. Excluding these two extremes points is justified by the fact that they highly affect the slope of the linear trend although they result from the mean of less than 50 pixels. For comparison, the other points in Figure 8 correspond to the average of about 5000 pixels. These biases are similar to the ones observed in the French Alps, suggesting that they are most likely due to errors in the SRTM-DEM and that biases in the SRTM-DEM may be present in most high mountain areas. These biases may be linked to the roughness of the topography (Surazakov and Aizen, 2006). For example, they were not detected on the gentle slope of the large glaciers of southeast Alaska (Larsen et al., in press).

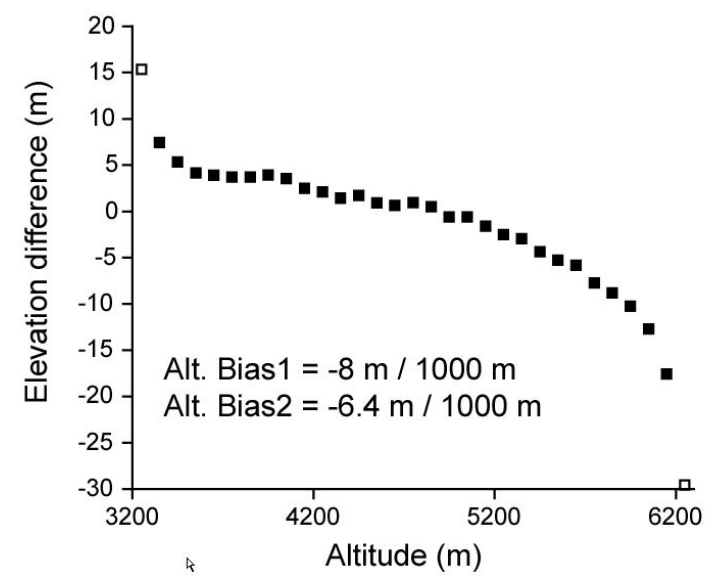

Figure 8: Biases between SRTM and the SPOT5 DEMs as a function of altitude on the ice free areas. The values of the linear biases with altitude are indicated in two cases. Alt Bias1 takes into account all the points whereas Alt Bias2 excludes the two extreme points.

As shown previously, such biases seriously affect any measurement of glacier surface elevation changes (Berthier et al., 2006). As the origin of these biases is not understood yet, we cannot apply a physically rigorous correction to SRTM elevations. Instead, we assume here that these biases are of similar magnitude on the glaciers and on the surrounding ice free zone. For each altitude interval, we correct the glacier elevation changes by subtracting the bias measured on the ice free areas. We also neglect the penetration of the $\mathrm{C}$-Band radar signal in the ice/snow cover. This penetration has not been studied for Himalayan glaciers but Rignot et al. (2001) have shown that the penetration depth can reach $4 \mathrm{~m}$ in the accumulation areas of Alaskan maritime glaciers.

After the biases between the two DEMs have been identified and corrected, glacial elevation changes can be computed and analyzed.

\section{Results: glacier inventory and elevation changes}

\subsection{2 glacier inventory based on the ASTER image}

A glacier inventory of our study area is required to (1) identify and correct the biases between the two DEMs on the ice free areas where no elevation changes should be 
observed (as detailed in section 3) and (2) to estimate the elevation changes and the mass balances of glaciers. Because the glacier boundaries are partly blurred out in the SPOT5 images by a recent snowfall, the inventory is derived from an ASTER image acquired the 28 September 2002 (Figure 9). The ASTER image is orthorectified using GCPs collected from the 12 November 2004 SPOT5 image and using a synthetic DEM obtained by filling data voids in SRTM-DEM using the SPOT5-DEM. Glacier boundaries are then delineated manually with an estimated accuracy of $+/-2$ pixels $(30 \mathrm{~m})$. Larger errors can exist on glacier tongues covered with debris or on steep slopes where the synthetic DEM is less accurate. A few glaciers were delineated from the 12 November 2004 SPOT5 image because of cloud/shadows on the ASTER image and also because a few glaciers present in the SPOT5 scenes (and DEM) were absent from the ASTER image (northwest corner of Figure 9). This inventory has been (or should be soon) added to the GLIMS database at http://glims.colorado.edu/glacierdata (Raup et al., in press). The total area digitalized covers $915 \mathrm{~km}^{2}$.

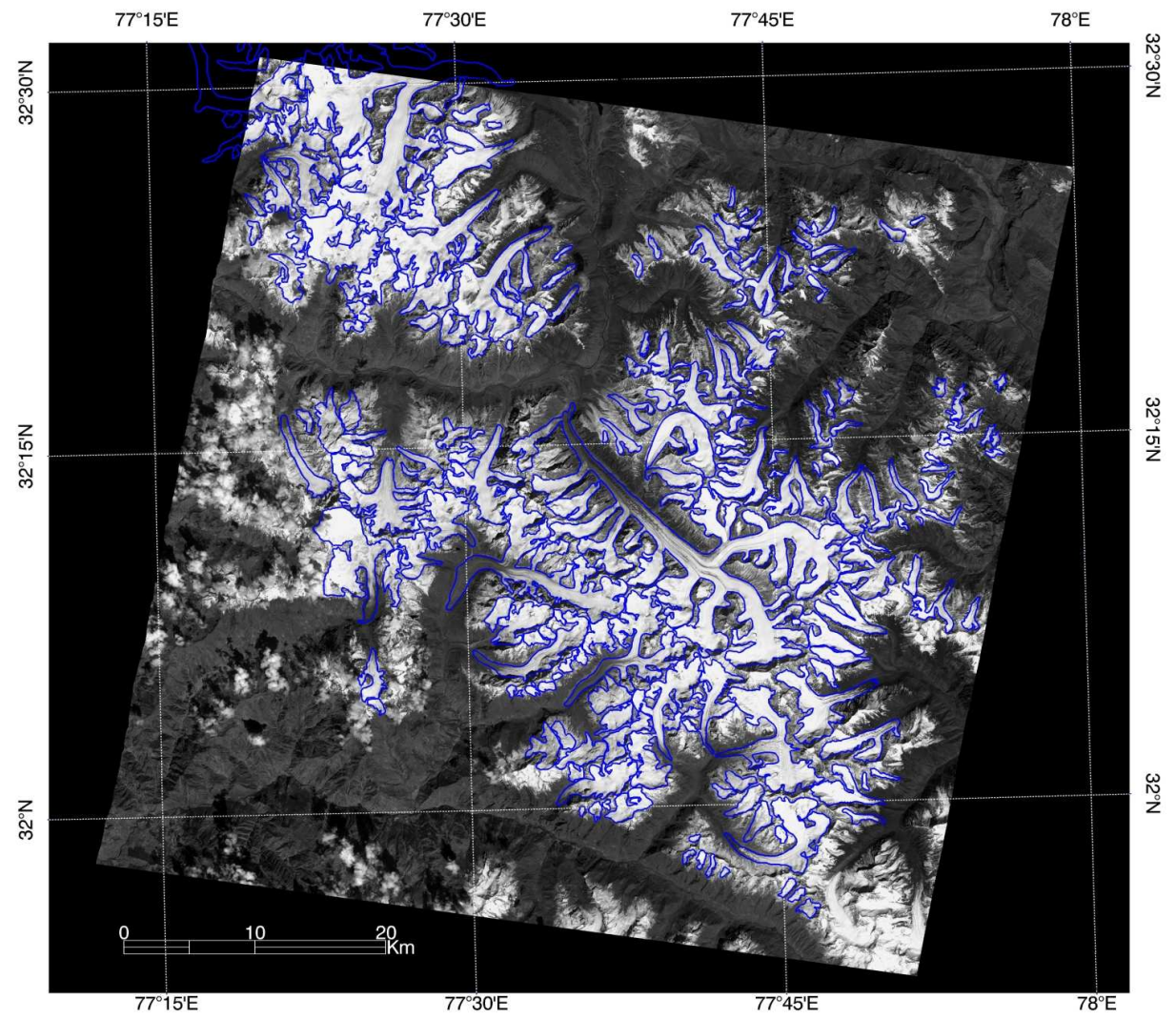

Figure 9: The glacier inventory for the Spiti/Lahaul region. Nearly $915 \mathrm{~km}^{2}$ of glaciers have been delimited from an ASTER image acquired in September 2002.

\subsection{Elevation changes}

Figure 10 is a map of the elevation changes on glaciers between February 2000 and November 2004. Even if some differences exist from one glacier to another, a clear thinning is observed on most of the glacier tongues, in particular for the largest glaciers 
which reach low elevations. Two glaciers groups (northern and southern) are distinguished to assess the consistency of our measurement at the local scale. The elevation changes are computed for altitude intervals of $100 \mathrm{~m}$ using a Gaussian filter that excludes inconsistent values (Berthier et al., 2004) and are presented in Figure 11. The thinning at low altitude is confirmed for the southern group but a slightly reduced thinning is measured at the lowest elevations, below $4300 \mathrm{~m}$. A similar feature has already been observed in other glacier regions (e.g. Arendt et al., 2002) and is due to the retreat of the glacier fronts which limits the thickness of ice available for melting. For the northern group, the glaciers seem to experience thickening or limited thinning below $4400 \mathrm{~m}$. However, in this group, the glacier area below $4400 \mathrm{~m}$ is limited to $7 \mathrm{~km}^{2}$ (out of $270 \mathrm{~km}^{2}$ ) and is just accounted for by a few glacier tongues. So this feature does not reflect a general behavior for the whole group. Between 4400 and $5000 \mathrm{~m}$, thinning of 4 to $7 \mathrm{~m}$ is observed for both glacier groups. Note a higher scatter of the data for the northern group. This is probably due to its smaller area compared to the southern group combined with the fact that averaging over a large number of glaciers reduces the errors in elevation changes.

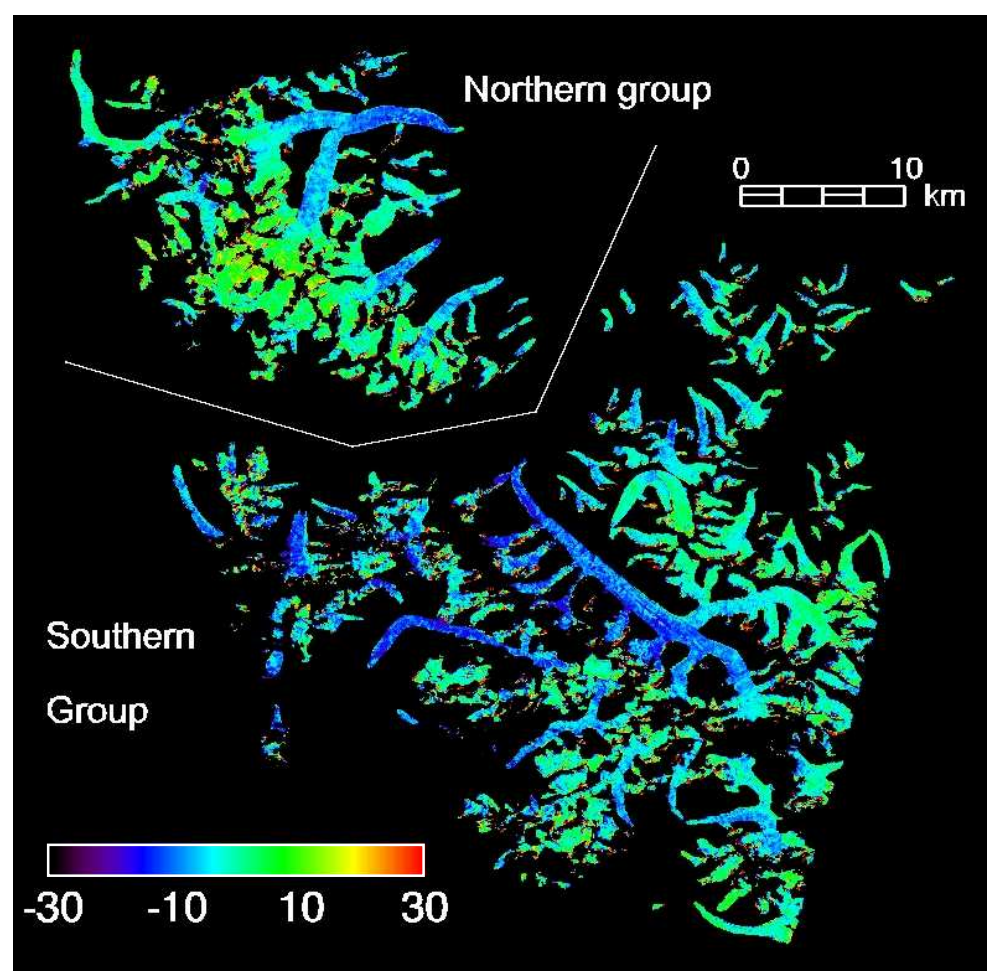

Figure 10: Map of the glacier elevation changes (in meters) between February 2000 and November 2004 for the glaciers in the Spiti/Lahaul region. Two glacier groups are distinguished depending on their location relatively to the Chandra River valley.

Most low elevation glacier tongues are covered with debris (Figure 9). Benn and Lehmkuhl (2000) or Tangborn and Rana (2000) indicates that ice ablation is reduced under debris as soon as the debris cover is thick enough (over 2 to $2.5 \mathrm{~cm}$ ). We do not have any measurement of debris thickness for the Spiti/Lahaul glaciers but field observations and visual inspection of the satellite images suggests important debris 
coverage on glacier tongues. Consequently, one might expect a limited thinning for these low elevation regions protected from the direct solar radiation. This is not the case and most debris-covered tongue experience thinning of 2 to $3 \mathrm{~m} / \mathrm{a}$ (compare Figure 9 and 10). We do not have any definitive explanation for these unexpected high thinning rates. Nakawo and Rana (1999) reported significant ablation rates (close to $0.5 \mathrm{~m} / \mathrm{a}$ ) on debris covered glaciers in Nepal. But it can only explain part of the measured elevation changes. Recent change in glacier dynamics (slow down) may contribute to this thinning. Surface velocity measurements (not shown here) were obtained by correlating the 13 November 2004 SPOT5 images with another SPOT5 image acquired 21 September 2005 following the methodology proposed by Berthier et al. (2005). The flow of the debris-covered part of Bara Shigri is slow (velocity smaller than $20 \mathrm{~m} / \mathrm{a}$ ) suggesting that downwasting may be the main process of glacier mass loss like in the Alps (Paul et al, in press). Yet, future work is required to document the changes of glacier flow with time and understand the surprisingly high thinning rates of the debris-covered tongues.

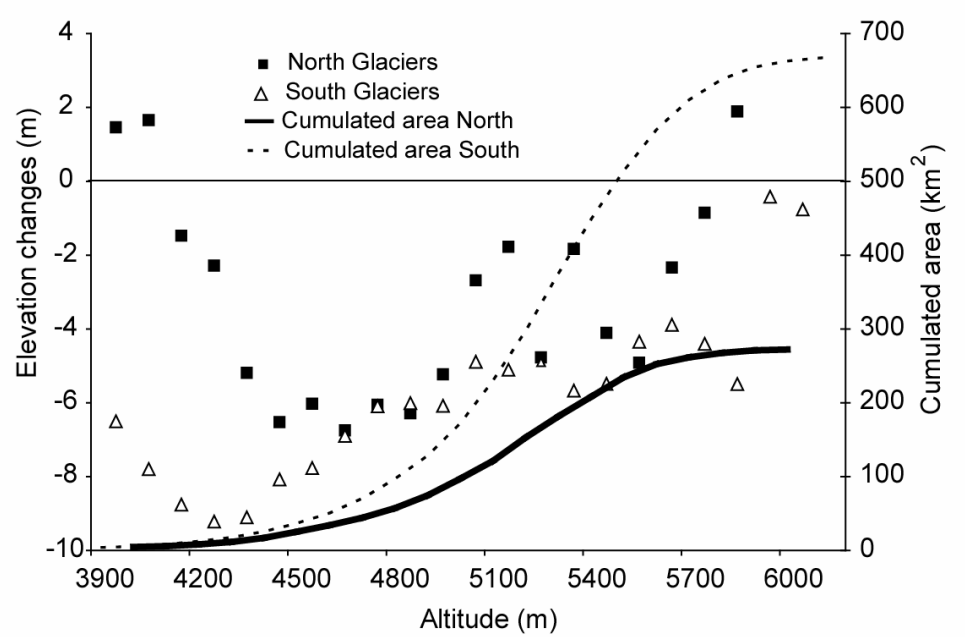

Figure 11: Thickness change as a function of altitude for the northern (black squares) and southern (white triangles) glacier groups defined in Figure 10. The cumulated areas are also shown for the two groups. Altitude intervals of $100 \mathrm{~m}$ are used.

Given the lack of in situ measurement, it is difficult to estimate the uncertainty associated with our surface elevation changes. It is also difficult to make a rigorous error analysis given the successive empirical adjustments of the DEMs. On the ice free area, the standard deviation of the difference between the two DEMs is high, $16 \mathrm{~m}(\mathrm{~N}=163100$ pixels). Yet, averaging all elevation changes for a large glacier area $\left(915 \mathrm{~km}^{2}\right.$ i.e., more than 100000 pixels) probably greatly reduces the errors. For a given altitude interval, the mean elevation change is computed as the average of about 4000 individual elevation changes. If these measurements were independent, one could argue that the uncertainties are reduced by a factor of 60 (the square root of 4000), leading to uncertainties of $0.27 \mathrm{~m}$ (or $0.05 \mathrm{~m} / \mathrm{a}$ ) only. However, we have shown that important biases exist in the two compared DEMs. These biases affect neighboring pixels in a similar way so that they cannot be considered as independent. In the French Alps, the comparison with precise topographic profiles has shown that satellite derived elevation changes, estimated every 
$50 \mathrm{~m}$ altitude intervals, are accurate within 1 to $2 \mathrm{~m}$ (Berthier et al., 2004). However, in the Alps, satellite DEMs were derived from SPOT images using an accurate set of GCPs and did not include any attitude bias (as in this study) or altitude-related bias (such as the one affecting the SRTM-DEM). Consequently, our elevation changes are less accurate in Himalaya than in the Alps but, due to the lack of ground truth data, we cannot provide here an uncertainty. In the following paragraph, we will see, however, that our measurements agree reasonably well with glacier mass balance measured in the field.

\subsection{Specific mass balances}

Elevation changes are now converted to mass balances using the hypsometry of each glacier or each glacier group. As shown previously for the French Alps (Berthier et al., 2006), the SRTM February 2000 DEM maps a surface which is close to the glacier surface at the end of the previous ablation season (October 1999). This is due to the penetration of the radar signal in the cold snow of the northern hemisphere winter months (December and January). For that reason, we consider here that the estimated mass balances are equivalent to the cumulative mass balance for five hydrological years between 1999 and 2004. The conversion of volume changes to mass balance requires the knowledge of the density of the material loss or gain. This is straightforward in the ablation zone where ice (density $900 \mathrm{~kg} / \mathrm{m}^{3}$ ) is involved. This is more problematic in the accumulation zone where two hypotheses are described in the literature.

Hypothesis 1: Following "Sorge's Law" (Paterson, 1994, p14), most authors assume that the density profile remains unchanged in the accumulation zone and consider that only ice (density $900 \mathrm{~kg} / \mathrm{m}^{3}$ ) is lost or gained (e.g. Arendt et al., 2002).

Hypothesis 2: Some studies consider instead that firn (density $600 \mathrm{~kg} / \mathrm{m} 3$ ) is gained or lost in the accumulation area (e.g. Haag et al., 2004). This hypothesis implies the knowledge of the equilibrium line altitude (ELA).

Hence, we prefer to compute the mass balances using the two hypotheses assuming a constant ELA of $5100 \mathrm{~m}$ for all glaciers (Table 2), considering that the real mass balance probably lies in-between these two end-members. The ELA we use here was determined on the field for the Chhota Shigri during hydrological years 2002-2003 and 2003-2004. A constant glacier area (determined on the ASTER 2002 image) is used to compute the specific mass balance.

Overall the mass balance for the $915 \mathrm{~km}^{2}$ of glaciers surveyed here is -0.7 to $-0.85 \mathrm{~m} / \mathrm{a}$ water equivalent (w.e.), corresponding to a total mass loss of $3.9 \mathrm{~km}^{3}$ of water in 5 years. The mass balance seems slightly more negative in the southern group $(-0.73$ to $-0.92 \mathrm{~m} / \mathrm{a}$ w.e.) than in the northern group $(-0.57$ to $-0.67 \mathrm{~m} / \mathrm{a}$ w.e.) but these differences are probably not significant given the uncertainties on our elevation changes. Rather, we think that the difference between the southern and northern groups (about 0.2 to $0.3 \mathrm{~m} / \mathrm{a}$ w.e. or 1.0 to $1.5 \mathrm{~m}$ of ice in 5 years) can be regarded as a first estimate of the uncertainties in our measurements. The sensitivity to the density of gain/loss material in the accumulation zone depends (obviously) on the size of the accumulation area relative to the whole glacier area. While considering firn instead of ice in the accumulation zone, 
the resulting difference on the mass balance is as high as $20 \%$. Note here that taking into account the penetration of the SRTM C-Band radar signal in the accumulation zone as proposed by Surazakov and Aizen (2006) would lead to even more negative mass balances.

Table 2: Total area, volume changes and specific mass balances between 1999 and 2004 in the Spiti/Lahaul region. A designs the total area; $A_{O K}$ the percentage of this area which is used to compute the elevation changes (different from $100 \%$ because of data voids in the SRTM or in the SPOT5 topography); $\Delta V$ the total volume changes (only calculated with the hypothesis 1 described in the text); $b_{1}$ and $b_{2}$ the specific mass balances computed using, respectively, hypothesis 1 and 2 described in the main text (section 4.3).

\begin{tabular}{llllll}
\hline Zone & $\mathrm{A}\left(\mathrm{km}^{2}\right)$ & $\mathrm{A}_{\mathrm{OK}}(\%)$ & $\Delta \mathrm{V}\left(\mathrm{km}^{3}\right)$ & $\mathrm{b}_{1}(\mathrm{~m} / \mathrm{a}$ w.e. $)$ & $\mathrm{b}_{2}(\mathrm{~m} / \mathrm{a}$ w.e. $)$ \\
\hline All glaciers & 915.5 & 66.5 & -3.87 & -0.85 & -0.69 \\
\hline Southern group & 653.6 & 60.9 & -2.96 & -0.91 & -0.72 \\
\hline Northern group & 261.9 & 78.3 & -0.91 & -0.67 & -0.57 \\
\hline Bara Shigri & 131.1 & 68.0 & -0.86 & -1.31 & -1.01 \\
\hline Chhota Shigri & 16.5 & 57.2 & -0.09 & -1.12 & -1.02 \\
\hline
\end{tabular}

In Table 2, we also included the mass balance for the Chhota and Bara Shigri glaciers (located in Figure 4). The later one is the largest of the region with an areal extent of 133 $\mathrm{km}^{2}$. It has a prominent, debris-covered glacier tongue (Figure 2) which experienced a significant thinning (over $10 \mathrm{~m}$ ) between 1999 and 2004 (Figure 9). The mass balance of Bara Shigri is -1 to $-1.3 \mathrm{~m} / \mathrm{a}$ w.e. The Chhota Shigri is the neighboring glacier to the east and its mass balance is monitored on the field since September 2002 (Figure 1c). The glaciological mass balances were $-1.06 \mathrm{~m} / \mathrm{a}$ w.e in 2002-2003 and -1.2 m/a w.e in 20032004 (Wagnon et al., in preparation). Note a high uncertainty for these specific field mass balances because of a limited coverage of the accumulation area. The space-derived specific mass balance for this glacier ( -1 to $-1.1 \mathrm{~m} / \mathrm{a}$ w.e.) is in agreement with the field mass balances which are, however, restricted to the later period of the space survey (Figure 12, upper panel).

According to NCEP/NCAR ${ }^{2}$ reanalysis (Figure 12), it seems that the earlier part of the space survey \{October 1999 - September 2002\} without ground measurements for Chhota Shigri is similar in term of annual precipitations and $500 \mathrm{hPa}$ temperatures to the later part \{October 2002 - September 2004\} where field mass balances exist. The mean temperatures for these two periods differ only by $0.07 \mathrm{~K}$ and the precipitations by $3 \mathrm{~mm}$, differences which are much smaller that the inter-annual variations of these two variables (Figure 12, central and lower panels). Consequently, the Chhota Shigri mass balances are probably also negative for the \{October 1999 - September 2002\} period and the agreement between space and field mass balances spanning different periods is not a coincidence. Note that we do not intend here to explain mass balances by fluctuations in temperature and precipitation. As pointed out by Dyurgerov and Meier (2000), the

\footnotetext{
${ }^{2}$ National Centers for Environmental Prediction / National Center for Atmospheric Research (NCEP/NCAR) reanalyses (Kalnay et al., 1996)
} 
“...process interrelating atmospheric circulation, surface meteorological parameters (e.g., air temperature and precipitation), and glacier DV is very complex" (where DV stands for volume changes). The pertinent meteorological variables driving the mass balance of glaciers in the Western Himalaya are not known and this is one goal of the field program that began on Chhota Shigri in 2002. We are also aware of the severe errors and biases that can affect the reanalysis in mountainous regions in particular the precipitations. This is why they are only used qualitatively here to compare the climatic conditions for two periods.
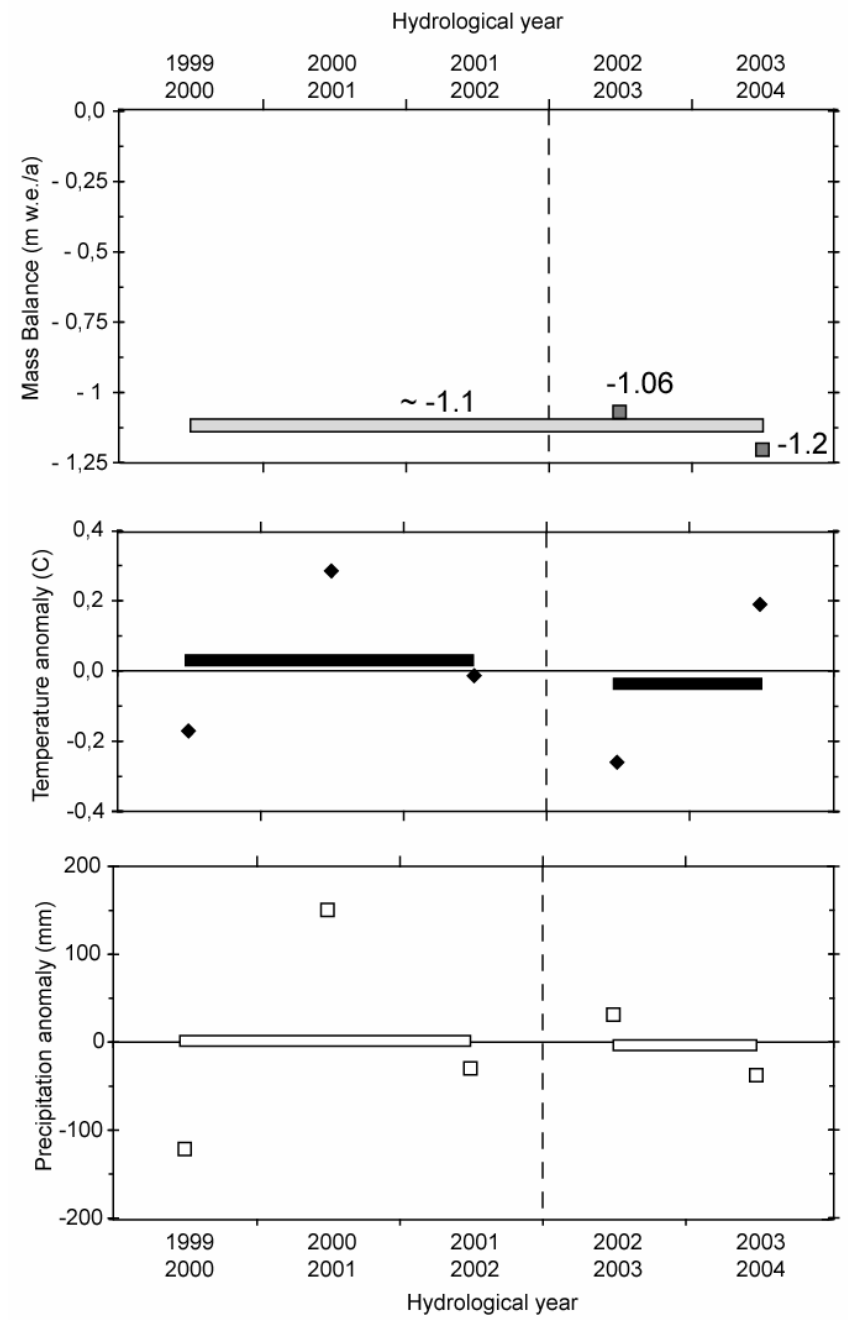

Figure 12: Upper panel: comparison of the specific mass balance (m/a w.e.) of the Chhota Shigri glacier measured in this study (1999-2004, light gray) and in the field for hydrological years 2002-2003 and 2003-2004 (darker gray squares). Central and lower panel: Anomalies (relative to the October 1999-September 2004 period) in mean annual temperature and annual precipitation from the NCEP/NCAR (National Centers for Environmental Prediction / National Center for Atmospheric Research) reanalysis. The vertical dashed line separates the hydrological years with (2002-2004) and without (1999-2002) ground measurements.

Our results are also in agreement with mass balance estimated in the nearby (about 100 $\mathrm{km})$ Baspa basin $\left(31.5^{\circ} \mathrm{N} ; 78.5^{\circ} \mathrm{E}\right)$ by using the accumulation area ratio (AAR) method 
(Kulkarni et al., 2004). As described in the introduction, these authors have established the relationship between the specific mass balance and the AAR using field measurements available on the Shaune Garang (period 1982-1988) and Gor Garang (1976-1984) glaciers (Kulkarni, 1992). Assuming that the snow line observed on satellite images at the end of the ablation season is a good proxy of the equilibrium line, they determine specific mass balance of -0.9 and $-0.78 \mathrm{~m} / \mathrm{a}$ (w.e.) for hydrological years 2000 2001 and 2001-2002. This is also in the range of our measurements. These two independent analyses suggest a rapid rate of glacier loss (about $-0.8 \mathrm{~m} / \mathrm{a}$ w.e.) in the Western Himalaya for the early $20^{\text {th }}$ century. These losses are at least twice higher than the average mass balance between 1977 and 1999 (-0.34 m/a w.e.) for the Himalaya (Dyurgerov and Meier, 2005, p101) indicating an increase in the pace of glacier wastage. Our finding agrees with the high rates of glacier thinning reported globally between 2001 and 2004 (Kaser et al., 2006).

Although we obtain a promising agreement between the remote sensing and field mass balances for the single Chhota Shigri glacier, we believe that our dataset of glacier volume changes is not accurate enough to analyze individual glacier mass balances. Nevertheless, averaging over a large number of glaciers distributed all over our images reduces the uncertainties and limits the impact of biases between the SPOT5 and SRTM DEM. Consequently, to discuss the relationship between glacier size and mass balance, we prefer to sort the glaciers into three main samples according to the individual glacier size: smaller then $10 \mathrm{~km}^{2}$, between 10 and $30 \mathrm{~km}^{2}$ and over $30 \mathrm{~km}^{2}$. We obtain three glacier samples whose total areas are similar (Table 3). All 3 glacier categories experienced negative mass balances. The 3 glaciers over $30 \mathrm{~km}^{2}$ recorded the highest ice losses, mostly because a significant fraction of these glaciers lies at low elevations where thinning is important. Future work and more accurate measurement of regional glacier elevation changes are required to systematically discuss the factors (glacier size, hypsometry, aspect, debris coverage, glacier dynamics) explaining the differences in mass balances.

Table 3: Total area and specific mass balances between 1999 and 2004 as a function of glacier size. A designs the area of each individual glacier ; $\Sigma$ A the cumulated area for each sample; $N$ the number of glaciers in each sample; $b_{1}$ and $b_{2}$ the specific mass balances computed using, respectively, hypothesis 1 and 2 described in the main text (section 4.3).

\begin{tabular}{lllll}
\hline Glacier area & $\Sigma \mathrm{A}\left(\mathrm{km}^{2}\right)$ & $\mathrm{N}$ & $\mathrm{b}_{1}(\mathrm{~m} / \mathrm{a}$ w.e. $)$ & $\mathrm{b}_{2}(\mathrm{~m} / \mathrm{a}$ w.e. $)$ \\
\hline $\mathrm{A}<10 \mathrm{~km}^{2}$ & 327.2 & 147 & -0.63 & -0.46 \\
\hline $10 \mathrm{~km}^{2}<\mathrm{A}<30 \mathrm{~km}^{2}$ & 333.9 & 19 & -0.60 & -0.51 \\
\hline $\mathrm{A}>30 \mathrm{~km}^{2}$ & 254.4 & 3 & -1.04 & -0.86 \\
\hline
\end{tabular}




\section{Conclusions}

In this study, we have combined SPOT5 images and Shuttle Radar Topographic Mission (SRTM) data to derive the 5-year specific mass balance of $915 \mathrm{~km}^{2}$ of glaciers in the Spiti/Lahaul region of Himachal Pradesh (India). The comparison of sequential glacier DEMs is able to capture the elevation changes for large (e.g. $60 \mathrm{~km} * 60 \mathrm{~km}$ ) and remote areas but must be done with caution. A rigorous assessment of the elevation changes on the stable areas surrounding the glaciers should be performed first before any conclusion is drawn concerning glacier evolution.

The SPOT5 digital elevation model (DEM) is obtained without in situ ground control points. Our methodology is thus potentially applicable to others remote glacial areas where a previous and sufficiently accurate DEM such as SRTM is available. This statement must be mitigated by the limited availability of some of the software we used (obtained from the French Space Agency) and the observation of important biases in both the SPOT5-DEM, due to a rapid change in the roll of the satellite, and the SRTM-DEM. In order to obtain correct elevations changes on glaciers, these biases need to be detected, understood and then removed. This is done empirically in this study by assuming that the ice free areas do not experience any significant elevation changes in 5 years. Note that for highly glaciated regions, where ice covers most of the satellite scene, such a correction would be more difficult to perform.

Future work should aim at producing DEMs with limited biases. For SPOT5, integrating the changes in attitudes (roll, pitch and yaw) in the satellite stereo model could result in significant improvements. One important source of uncertainties in our study is the lack of understanding of SRTM biases related to slope (Surazakov and Aizen, 2006) and/or elevation (Berthier et al., 2006) and those linked to the penetration of the radar signal in the cold snow at high elevations. Also, we believe that subtracting topographies derived from a unique satellite sensor would lead to better results. In the near future, we hope to compare topographies derived from SPOT5 stereo images only.

Between fall 1999 and November 2004, the $915 \mathrm{~km}^{2}$ of glaciers digitized on an ASTER image have experienced significant thinning at low elevations ( 8 to $10 \mathrm{~m}$ below $4400 \mathrm{~m}$ ) and limited elevation changes at higher elevations (slight thinning of about $2 \mathrm{~m}$ ). The uncertainties associated with these elevation changes are difficult to quantify given the lack of ground measurements. However, a promising agreement is found between the space (-1 to $-1.1 \mathrm{~m} / \mathrm{a}$ w.e. for $1999-2004)$ and field (-1.13 m/a w.e. for 2002-2004) mass balances for the Chhota Shigri glacier. The overall specific mass balance is -0.7 to -0.8 $\mathrm{m} / \mathrm{a}$ w.e., showing that glaciers of the Spiti/Lahaul region are experiencing rapid ice losses. These losses are at least twice higher than the average mass balance between 1977 and 1999 (-0.34 m/a w.e.) for the Himalaya (Dyurgerov and Meier, 2005) indicating an increase in the pace of glacier wastage. In future work, we hope to extend our work to other regions of Himalaya and Karakorum to assess whether the glacier shrinkage reported here is homogenous at the scale of the mountain range and to better understand its link with regional climate changes. 


\section{Acknowledgments}

The comments by three anonymous reviewers and Marvin E. Bauer (Editor-in-Chief) led to major improvements in our manuscript. SPOT5 images were purchased thanks to the ISIS program (copyright CNES). The ASTER image was obtained for free thanks to the GLIMS program. E.B. acknowledges a Marie Curie Outgoing International Fellowship from the European Union. The field work on Chhota Shigri glacier has been performed between 2002 and 2004 through a MOU signed between Institut de Recherche pour le Développement (GreatIce unit) - France and the Jawaharlal Nehru University (New Delhi) - India, with the support of the French Embassy in India, the Commission for Cryospheric Sciences of IUGG and the Hindu Kush Himalaya sector of the UNESCO / FRIEND program.

\section{References}

Ageta, Y., Iwata, S., Yabuki, H., Naito, N., Sakai, A., Narama, C., and Karma T. (2000). Expansion of glacier lakes in recent decades in the Bhutan Himalayas. In M. Nakawo, C. F. Raymond and A. Fountain (Eds.), Debris-Covered Glaciers, vol. 264. IAHS Publications.

Arendt, A.A., Echelmeyer, K.A., Harrison, W.D., Lingle, C.S and Valentine, V.B. (2002). Rapid wastage of Alaska glaciers and their contribution to rising sea level, Science, 297, 382-386, doi:10.1126/science.1072497.

Barnett, T.P., Adam, J.C. and Lettenmaier, D.P. (2005). Potential impacts of a warming climate on water availability in snow-dominated regions, Nature, 438 (7066), 303-309, doi:10.1038/nature04141.

Benn, D.I. and Lehmkuhl, F. (2000). Mass balance and equilibrium-line altitudes of glaciers in high-mountain environments, Quatern. Int., 65-66 (2000), 15-29.

Berthier, E., Arnaud, Y., Baratoux, D., Vincent, C. and Remy, F. (2004). Recent rapid thinning of the "Mer de Glace" glacier derived from satellite optical images, Geophys. Res. Lett., 31 (17), L17401, doi:10.1029/2004GL020706

Berthier, E., Vadon, H., Baratoux, D., Arnaud, Y., Vincent, C., Feigl, K.L., Remy, F. and Legresy, B. (2005). Mountain glacier surface motion derived from satellite optical imagery. Remote Sensing Environ., 95 (1), 14-28.

Berthier, E., Arnaud, Y., Vincent, C. and Remy, F. (2006). Biases of SRTM in high-mountain areas: Implications for the monitoring of glacier volume changes, Geophys. Res. Lett., 33 (8), L08502, doi:10.1029/2006GL025862

Bishop, M.P., Shroder, J.F. and Ward, J.L. (1995). SPOT multispectral analysis for producing supraglacial debris_load estimates for Batura Glacier, Pakistan. Geocarto International, 10, $81-90$.

Bishop, M.P., Kargel, J.S., Kieffer, H.H., MacKinnon, D.J., Raup, B.H. and Shroder, J.F. (2000). Remote-sensing science and technology for studying glacier processes in High Asia, A. Glaciol., 31, 164-170.

Bouillon, A., Bernard, M., Gigord, P., Orsoni, A., Rudowski, V., Baudoin, A. (2006). SPOT 5 HRS geometric performances: using block adjustment as a key issue to improve quality of DEM generation. ISPRS J. Photogramm., 60(3), 134-146. 
Carabajal, C.C. and Harding, D.J. (2006). SRTM C-band and ICESat laser altimetry elevation comparisons as a function of tree cover and relief. Photogramm. Eng. Remote Sens., 72(3), $287-298$.

Dyurgerov, M.B. and Meier, M.F. (2000). Twentieth century climate change: Evidence from small glaciers. Proc Natl Acad Sci USA, 97(4), 1406-1411.

Dyurgerov, M.B. and Meier, M.F. (2005). Glaciers and the changing earth system: a 2004 snapshot. Occasional Paper \#58 http://instaar.colorado.edu/other/download/OP58 dyurgerov meier.pdf.

Haag, W.J., Braun, L.N., Uvarov, V.N. and Makarevich, K.G. (2004). A comparison of three methods of mass balance determination in the Tuyuksu glacier region, Tien Shan, Central Asia. J. Glaciol., 50 (171), 505-510.

Kääb, A. (2005). Combination of SRTM3 and repeat ASTER data for deriving alpine glacier flow velocities in the Bhutan Himalaya. Remote Sensing Environ., 94 (4), 463-474.

Kääb, A., Huggel, C., Fischer, L., Guex, S., Paul, F., Roer, I., Salzmann, N., Schlaefli, S., Schmutz, K., Schneider, D., Strozzi, T. and Weidmann, Y. (2005). Remote sensing of glacierand permafrost-related hazards in high mountains: an overview. Natural Hazards and Earth System Science, 5, 527-554, sRef-ID: 1684-9981/nhess/2005-5-527.

Kalnay, E. and 22 others (1996). The NCEP/NCAR 40-year reanalysis project. B. Am. Meteorol. Soc., 77(3), 437-471.

Kargel, J., Abrams, M., Bishop, M., Bush, A., Hamilton, G., Jiskoot, H., Kääb, A., Kieffer, H., Lee, E., Paul, F., Rau, F., Raup, B., Shroder, J., Soltesz, D., Stainforth, D., Stearns, L. and Wessels, R. (2005). Multispectral imaging contributions to global land ice measurements from space. Remote Sensing Environ., 99(1-2), 187-219.

Kaser, G., Cogley, J.G., Dyurgerov, M.B., Meier, M.F. and Ohmura, A. (2006). Mass balance of glaciers and ice caps: Consensus estimates for 1961-2004, Geophys. Res. Lett., 33, L19501, doi:10.1029/2006GL027511.

Kaul, M.K. (1999). Inventory of the Himalayan Glaciers: A Contribution to the International Hydrological Programme/edited by M.K. Kaul., 165 p.

Kulkarni, A.V. (1992). Mass balance of Himalayan glaciers using AAR and ELA methods. $J$. Glaciol., 38(128), 101-104.

Kulkarni, A.V., Rathore, B.P. and Alex, S. (2004). Monitoring of glacial mass balance in the Baspa basin using Accumulation Area Ratio method. Curr. Sci., 86, 101-106.

Kumar, S. and Dobhal, D.P. (1997). Climatic effects and bed rock control on rapid fluctuations of Chhota Shigri glacier, northwest Himalaya, India. J. Glaciol., 43(145), 467-72.

Larsen, C.F., Motyka, R.J., Arendt, A.A., Echelmeyer, K.A. and Geissler, P.E. (in press) Glacier changes in southeast Alaska and contribution to sea level rise, J. Geophys. Res.

Paterson, W. S. B. (1994). The physics of glaciers, 3rd Edition. Pergamon, New York.

Nakawo, M. and Rana, B. (1999). Estimate of ablation rate of glacier ice under a debris layer. Geografiska Annaler, 81A, 695-701.

Paul, F, Kääb, A and Haeberli, W. (in press). Recent glacier changes in the Alps observed by satellite: Consequences for future monitoring strategies, Global Planet. Change, doi:10.1016/j.gloplacha.2006.07.007 
Rabus, B., Eineder, M., Roth, A. and Bamler, R. (2003). The shuttle radar topography mission. A new class of digital elevation models acquired by spaceborne radar, ISPRS J. Photogramm. Remote Sens., 57, 241- 262.

Raup, B.R., Racoviteanu, A., Khalsa, S.J.S., Helm, C., Armstrong, R. and Arnaud, Y. (in press). The GLIMS geospatial glacier database: A new tool for studying glacier change, Global Planet. Change, doi:10.1016/j.gloplacha.2006.07.018.

Reinartz, P., Müller, R.. Lehner, M. and Schroeder, M. (2006). Accuracy analysis for DSM and orthoimages derived from SPOT HRS stereo data using direct georeferencing. ISPRS J. Photogramm., 60(3), 160-169.

Rignot, E., Echelmeyer, K. and Krabill, W. (2001). Penetration depth of interferometric syntheticaperture radar signals in snow and ice. Geophys. Res. Lett., 28 (18), 3501-3504.

Rodríguez, E., Morris, C.S. and Belz, J.E. (2006). A Global Assessment of the SRTM Performance. Photogramm. Eng. Remote Sens., 72(3), 249-260.

Roy, S.S. and Balling Jr.R.C. (2005). Analysis of trends in maximum and minimum temperature, diurnal temperature range, and cloud cover over India, Geophys. Res. Lett., 32(12), L12702, doi:10.1029/2004GL022201.

Seko, K., Yakubi, H., Nakawo, M., Kadiota, T. and Yamada, Y. (1998), Changing surface features of Khumbu glacier, Nepal Himalayas revealed by SPOT images, Bull. Glacier Res., $16,33-41$.

SPOT Image, (2002). SPOT Satellite Geometry Handbook, SNT-73_12-SI, Edition 1, Revision 0.

Surazakov, A.B. and Aizen, V.B., (2006). Estimating volume change of mountain glaciers using SRTM and map-based topographic data. IEEE T. Geosci. Remote, 44 (10), 2991- 2995.

Tangborn, W. and Rana, B. (2000). Mass balance and runoff of the partially debris-covered Langtang glacier, Nepal. In M. Nakawo, C. F. Raymond and A. Fountain (Eds.), DebrisCovered Glaciers, vol. 264. IAHS Publications.

Toutin, T. (2002). Three-dimensional topographic mapping with ASTER stereo data in rugged topography. IEEE T. Geosci. Remote, 40 (10), 2241-2247.

Toutin, T. and Cheng, P. (2002). A comparison of automated DEM extraction results using alongtrack ASTER and across-track SPOT stereo images. Opt. Eng., 41, 2102- 2106.

Toutin, T. (2004). Geometric processing of remote sensing images: models, algorithms and methods. Int. J. Remote Sens., 25 (10), 1893-1924.

Wagnon et al. Four years of field mass balance measurements of an Himalayan glacier (Chhota Shigri) in the Lahaul and Spiti region, India. In preparation.

Wessels, R., Kargel, J.S. and Kieffer, H.H. (2002). ASTER measurements of supraglacial lakes in the Mount Everest region of the Himalaya. A. Glaciol., 34, 399-408.

WWF (2005). An overview of glaciers, glacier retreat, and subsequent impacts in Nepal, India and China. Available at http://assets.panda.org/downloads/himalayaglaciersreport2005.pdf

Yadav, R.R., Park, W.K., Singh, J. and Dubey, B. (2004). Do the western Himalayas defy global warming? Geophys. Res. Lett., 31(17), doi:10.1029/2004GL020201 